\title{
Eleições, estabilidade democrática e socialização política no Brasil: análise longitudinal da persistência de valores nas eleições presidenciais de 2002 a 2010
}

\author{
Marcello Baquero \\ Programa de Pós-Graduação em Ciência Política \\ Universidade Federal do Rio Grande do Sul \\ Rodrigo Stumpf Gonzalez \\ Programa de Pós-Graduação em Ciência Política \\ Universidade Federal do Rio Grande do Sul
}

\begin{abstract}
Resumo: $O$ objetivo deste artigo é examinar os debates recentes sobre os fatores que explicam a estabilidade democrática no Brasil. Com base no conceito de socialização política examina-se o impacto que as eleições têm no fortalecimento democrático e a importância de normas e valores para o futuro da democracia. Considera-se que as eleições presidenciais no contexto político brasileiro se constituem em um momento importante do processo de socialização política. Para verificar esta proposição este trabalho utiliza como base de dados as pesquisas do Estudo Eleitoral Brasileiro (ESEB) de 2002, 2006 e 2010. É analisado se o fator idade gera diferenças em relação aos valores e atitudes manifestados pelos entrevistados com um tempo maior de experiência democrática, contribuindo na formação de uma cultura política congruente com a democracia, ou se são definidos pelo contexto eleitoral, tendo como base a divisão da população em coortes por faixa etária e na escolha eleitoral em cada pleito. Com base nos dados analisados identifica-se uma mudança da cultura política em direção à valorização da democracia, mas com a manutenção de contradições que indicam a manutenção de uma cultura híbrida, que não favorece a democracia representativa poliárquica.
\end{abstract}

Palavras chave: Democracia; socialização política; cultura política; CSES-ESEB 2010

\begin{abstract}
The main objective of this article is to examine the recent debates about the factors that explain democratic stability in Brazil. Based upon the concept of political socialization it analyses the impact of elections on the strengthening of democracy and the importance of norms and values for the future of democracy. We think that presidential elections in the Brazilian case could be characterized as an important moment in the political socialization process. To test this proposition we use the data from the Brazilian Electoral Study (ESEB) conducted in 2002, 2006 and 2010. It is analyzed if age generates differences in the values and attitudes manifested by people, with more democratic experience leading, to the materialization of a political culture congruent with democracy, or if they are defined by the electoral context, analyzing the dimensions dividing population by cohorts by age, and by electoral choice in each turnout. We conclude that political culture has changed to support more democratic values, but the contradictions remaining indicates a hybrid culture that does not favor a poliarchic representative democracy.
\end{abstract}

Keywords: Democracy; political socialization; political culture; CSES-ESEB 2010

OPINIÃO PÚBLICA, Campinas, vol. 17, n² 2, Novembro, 2011 , p.369-399 


\section{Introdução}

O estudo dos fatores que explicam a estabilidade democrática no Brasil tem se constituido um tema central da Ciência Política no período recente. No cerne desse discurso está o debate dos cientistas políticos em relação ao papel das instituições políticas, seja como mecanismo de representação e tomada de decisões, seja no desenvolvimento de cidadãos críticos e com capacidade de intervenção e a relação mútua entre estes dois aspectos na estabilidade do regime.

A premissa básica dessas perspectivas pressupõe que instituições eficientes não somente auxiliam a promover uma sociedade civil vigorosa e participativa, mas, sobretudo, contribuem para produzir bases de legitimidade das autoridades públicas, gerando como corolários, a confiança institucional e interpessoal. Neste sentido, uma das principais instituições na promoção de um maior grau de engajamento político dos cidadãos é o processo eleitoral, na medida em que estimularia e motivaria as pessoas a participarem pelo efeito de demonstração e de socialização política.

Em outras palavras, as eleições, em qualquer nível eleitoral em que ocorram funcionariam como dispositivos pedagógicos positivos para os cidadãos, pois quanto mais experiências com essa prática cívica, maior a probabilidade de internalizar valores democráticos eleitorais por meio do processo de incorporação e institucionalização de crenças que valorizem a mobilização e participação políticas, produzindo cidadãos educados a respeito de assuntos políticos e com atitudes de tolerância e cooperação.

No entanto, no caso do Brasil das últimas três décadas, observa-se uma assimetria onde, por um lado, há uma decomposição de práticas políticas antigas que funcionavam na base do corporativismo e do clientelismo, e, ao mesmo tempo, surgem iniciativas incipientes de natureza democrática que geram novos equilíbrios, mas que, em virtude do cenário assimétrico, tendem a reproduzir as práticas que visavam eliminar.

Nesse contexto, uma opinião corrente a respeito das eleições é de que elas têm se convertido em pesquisas de popularidade centradas em questões triviais, que enfatizam a dimensão pessoal do candidato em detrimento de questões substantivas e programáticas. Nesse cenário, do ponto de vista da maioria dos cidadãos, as eleições seriam consideradas como pleitos entre grupos minoritários poderosos que perseguem os mesmos interesses, e que competem na busca do poder para favorecer os interesses dos seus respectivos grupos. Desse modo, os novos padrões de participação política, eminentemente de natureza formalprocedimental, que têm surgido com a institucionalização de pleitos eleitorais, não 
BAQUERO, M.; GONZALEZ, R. S. Eleição, estabilidade democrática e socialização política...

teriam produzido mudanças políticas estruturais efetivas de caráter atitudinal e comportamental.

Em nossa opinião, tal processo pode gerar uma persistência de atitudes e comportamentos na arena política que não redundam, necessariamente, em uma estabilidade política democrática, ou seja, a repetição do voto em um mesmo partido ou candidato não prediz identificação ideológica partidária de forma sólida, pois o personalismo parece continuar vigente, e forte, como captador de votos.

Essa situação propiciou o ressurgimento da necessidade de debater a congruência entre a dimensão política institucional e o tipo de cultura política de um país. Uma questão central dessa discussão diz respeito ao impacto que as eleições têm no fortalecimento democrático e se o apoio popular a normas e valores democráticos são indispensáveis para o futuro da democracia.

Embora exista um reconhecimento de que a democracia representativa envolve uma cidadania ativa envolvida na política, estamos longe de constituir mecanismos eficientes de engajamento político, além da dimensão meramente formal-eleitoral. Isto se deve, entre outros fatores, à forma e tipo de valores políticos que são transmitidos de geração para geração. A não compreensão desse processo produz um conhecimento meramente reativo e descritivo que segue diretrizes teóricas convencionais.

Assim, o quanto a socialização política pode nos dizer sobre o sistema político e quanto podemos conhecer do processo eleitoral recente no Brasil, estudando a constituição das atitudes através do processo de socialização dos eleitores?

Neste trabalho, queremos examinar o papel dos processos eleitorais no processo de socialização política, verificando se as eleições presidenciais realizadas no Brasil no período 2002-2010 serviram como mobilizadoras do voto, no sentido individual, ou se de uma eleição para outra são construídos valores que persistem estruturalmente, ao longo do tempo. O objetivo é examinar se as eleições no Brasil contribuem para a geração de valores democráticos nos cidadãos e, conseqüentemente, operam como indutoras de atitudes e comportamentos políticos auxiliando no processo de estabilidade democrática. Para isso, examinamos os dados das pesquisas do Estudo Eleitoral Brasileiro (ESEB) ${ }^{1}$ das três ultimas eleições presidenciais trabalhando com coortes, levando-se em conta que a socialização política é um processo permanente que perpassa toda a vida do indivíduo.

\footnotetext{
${ }^{1}$ O ESEB é uma pesquisa pós-eleitoral de natureza acadêmica associada ao Projeto Comparative Study of Electoral Systems, da University of Michigan, coordenado por Rachel Meneguello (CESOP/Unicamp)
} 
A função da socialização política, no que se refere a processos eleitorais, é a de proporcionar suporte para a persistência do sistema político, na medida em que todo sistema busca a sua persistência, o que inclui os procedimentos próprios da estabilidade, bem como assimilação de profundas modificações em decorrência das constantes pressões. A base sobre a qual o apoio ao sistema político se constitui pela socialização política, de acordo com Easton (1965) é de dois tipos. O "apoio específico", que envolve respostas concretas do sistema em relação a demandas determinadas, podendo "aumentar ou declinar sempre que os membros interpretam as conseqüências dos diversos 'outputs' do sistema", e o "apoio difuso" que diz respeito à confiança institucional das pessoas.

Um sistema político alcança estabilidade formal quando, do ponto de vista da socialização política os cidadãos internalizam a necessidade de obediência às autoridades legalmente constituídas, assim como a necessidade de os indivíduos limitarem as demandas dirigidas ao sistema, o qual nunca consegue satisfazê-las na sua totalidade.

A socialização política é um elemento que só pode ser compreendido no conjunto do sistema político; sua função é propiciar condições psicoculturais favoráveis à persistência do sistema; mas persistência inclui tanto estabilidade, quanto mudança, e a socialização não se confundem com a reprodução do status quo, na medida em que pode potencializar os elementos de instabilidade.

A relevância teórica da pesquisa sobre cultura e socialização política está em buscar uma compreensão das condições de estabilização da democracia nas suas dimensões formal e societal, ou seja, indo além da perspectiva formalista, restrita aos marcos do liberalismo, que prevaleceu em boa parte dos estudos desde a década de 1960.

\section{Eleições e socialização política}

Para Easton e Dennis (1969) não basta uma teoria geral sobre a socialização nem uma teoria da socialização política: é preciso uma "teoria política da socialização política"; a "teoria alocativa", que se ocupa basicamente da esfera partidária a "análise da estabilidade sistêmica", que vincula a socialização à manutenção do sistema e a "teoria sistêmica", desenvolvida com base no referencial proposto por Easton (teoria dos inputs-outputs). Nesta perspectiva, para alguns autores, os processos eleitorais fundamentalmente ativam as predisposições políticas latentes (LAZARSFELD ET ALLI, 1968, p.73). As predisposições seriam, por exemplo, as variáveis sociológicas, tais como o nível econômico, grau de sofisticação política e nível de escolaridade. Segundo esses autores, a ativação se produz quando as tendências políticas latentes se manifestam no voto. Além da 
BAQUERO, M.; GONZALEZ, R. S. Eleição, estabilidade democrática e socialização política...

ativação latente, as campanhas eleitorais segundo esses autores servem também para reforçar a intenção do voto, evitando que de uma eleição para outra haja perda de eleitores, e, finalmente, processos eleitorais proporcionam as oportunidades para converter os eleitores a mudar seu voto de uma eleição para outra.

De maneira geral, a produção acadêmica sobre comportamento eleitoral no Brasil segue a tendência da produção internacional que, ao longo do tempo, tem salientado a abordagem sociológica, que tem como representantes (Seymour Lipset, Stein Rokkan, Bernard Berelson e Paul Lazarsfeld), cujo principal atributo é salientar fatores de longo prazo, por exemplo, aspectos econômicos, religiosos e regionais (ANTUNES, 2008). A abordagem psicossociológica (CAMPBELL ET ALLI, 1960) enfatiza a identificação partidária, originada no processo de socialização e pautada em tradições familiares, como principal fator de longo prazo na decisão de voto. Nesta perspectiva, se avaliam atitudes, motivações e percepções dos eleitores em relação aos partidos e candidatos. Uma terceira abordagem se refere à teoria da escolha racional, a qual enfatiza o individualismo metodológico proposto pela teoria downsiana. Essa perspectiva teórica examina o voto a partir de uma base lógica racional com base em um cálculo de custo-benefício. Basicamente, subjacente a esta perspectiva, está a idéia que há uma busca para maximizar ou otimizar ganhos, como consumidores de um mercado, por parte de indivíduos racionais (CASTRO, 1992).

A esses fatores podem se acrescentadas outras variáveis de caráter contextual. Por exemplo, o eleitor brasileiro tem sido caracterizado como intuitivo e não racional (SILVEIRA, 1994), "sofisticado" (CASTRO, 1994), "personalista e pragmático" (BAQUERO, 2007), "tipo Flamengo" (REIS, 1988), "racional" (FIGUEIREDO, 1991), além do papel do "voto identitário" na definição do voto (ALBUQUERQUE, 1992; BALBACHEVSKY e HOLZHACKER, 2004), e da influência da construção de identidades coletivas no campo eleitoral. $O$ interesse em entender o sentido de identidade coletiva está em identificar até que ponto eventos políticos tidos como relevantes constituem fatores desencadeadores de atitudes e comportamentos diferenciados em um grupo etário.

Neste sentido, os conhecimentos sobre instituições, personagens e eventos políticos, bem como a capacidade de interpretar conceitos políticos abstratos, materializam-se com o amadurecimento das estruturas cognitivas do indivíduo. Essas caracterizações, em nossa opinião, estão amparadas em um processo pouco estudado na ciência política brasileira, e que diz respeito ao processo de socialização política.

Nas três últimas décadas, tem se institucionalizado, na compreensão e explicação de processos eleitorais, a dimensão cultural, pela importância que the é 
atribuída para a estabilidade e legitimidade de um regime democrático. Refere-se, portanto, a como as atitudes e comportamento políticos dos cidadãos operam enquanto instâncias complementares do desenvolvimento democrático de um sistema político. O principal desafio para o fortalecimento democrático, tendo em vista que avanços formais e procedimentais não têm sido suficientes para alcançar um ideal democrático participativo, é o de como estimular a formação de atitudes e comportamentos políticos que valorizem as práticas e os ideais democráticos em um país como o Brasil onde a cultura política está longe de ser participativa e cívica.

A socialização política examina como se formam as atitudes políticas nos indivíduos por meio da transmissão de valores e crenças num sentido geracional. São esses valores e crenças que formatam um determinado tipo de cultura política (ALMOND e VERBA, 1965). Os primeiros estudos foram conduzidos por Herbert Hyman no seu livro Political Socialization (1959), no qual argumentava que a socialização política tem seu início na infância: "Está claro em todas as três áreas de investigação, participação política, orientação política e tendências autoritárias vs. tendências democráticas, que diferenças entre adultos têm suas origens nos primeiros estágios de desenvolvimento", sendo o mais importante o que diz respeito à identificação partidária.

Opinião semelhante é compartilhada por Easton e Dennis (1969). Na discussão do seu modelo de análise de sistemas, o autor conceitua a política como um campo que inclui à formação de demandas e suportes (inputs), e de decisões obrigatórias (outputs), que ultrapassam em muito o campo da política alocativa (partidária). Para o autor, as crianças têm pouca intimidade com a política partidária, mas têm experiências, opiniões e sentimentos sobre outros aspectos do sistema político, que podem ser visualizados em quatro dimensões: (1) a politização: a sensibilização difusa à política; (2) a personalização: o contato com o sistema político através de certas figuras com autoridade; (3) a idealização da autoridade: a autoridade é vista como benéfica ou prejudicial; (4) a institucionalização: a criança passa da visão personalizada para uma concepção impessoal de sistema político.

Em 1960, David Easton, Jack Dennis, Robert Hess e outros, realizaram uma pesquisa com mais de 12.000 crianças norte-americanas que teve impacto significativo na área de cultura política, sobretudo, com o livro, Children in the political System: Origins of Political Legitimacy (1969). Importantes estudos surgiram, posteriormente, principalmente em relação ao papel da família no processo de socialização política, não como entidade central, mas incorporando aspectos econômicos e socioculturais (JENNINGS E NIEMI, 1974). A escola passou a ser 
BAQUERO, M.; GONZALEZ, R. S. Eleição, estabilidade democrática e socialização política...

considerada instituição crucial na estruturação da personalidade política, sobretudo, na identificação política dos indivíduos.

Na Europa, Annick Percheron e Charles Roig, buscaram compreender como contextos precedentes impactavam a estruturação de atitudes políticas, incorporando fatores socioeconômicos, indo, portanto, além da influência da estrutura familiar. Esta abordagem é útil neste trabalho na medida em que possibilita analisar que fatores, além dos convencionais, explicam o comportamento eleitoral em um sentido longitudinal. Isto não significa que valores internalizados na infância e na adolescência em relação à política não sejam importantes na avaliação do comportamento eleitoral de adultos, pois muitos deles trazem consigo imagens e crenças sobre o mundo político, considerado costumeiramente como um "jogo sujo" (EASTON e DENNIS, 1969, p.82). Desse modo, a política seria uma área de adultos e suas atitudes e comportamentos decorreriam de suas experiências nessa faixa etária.

Do ponto de vista da teoria da cultura política, o estudo de Almond e Verba, em The Civic Culture, postulou o princípio de que quanto maior o espaço de participação nas decisões na família e nos debates na escola, maior a confiança do indivíduo de que suas ações podem influenciar as decisões políticas que the dizem respeito (ALMOND e VERBA, 1965, p.300).

Esse modelo foi definido pelo princípio de primazia com base em três premissas: (a) as orientações políticas são aprendidas durante a infância; (b) o aprendizado infantil modela qualquer modificação posterior; (c) escala das modificações posteriores é pequena.

Esse modelo foi questionado na França com base no argumento de que a socialização é um processo permanente, que ocorre por toda a vida. Nessa linha de análise, não se pode estabelecer uma linha de continuidade entre as atitudes infantis e as adultas, porque as atitudes adultas são mais estáveis; na adolescência há uma ruptura com o mundo infantil e um empréstimo de idéias do mundo dos adultos; os eventos (casamento, trabalho, serviço militar, mudança de meio social ou geográfico) podem modificar as atitudes constituídas (PERCHERON, 1971, p.147).

Já para Sigel (1989) a socialização política adulta é essencialmente um fenômeno interativo entre a dimensão individual e a social; é caracterizada tanto pela mudança como pela continuidade. A autora enfatiza o impacto dos processos e eventos históricos, sem desconhecer a singularidade de cada indivíduo, especificado pela personalidade política individual. A mudança e a continuidade são percebidas. 
As recentes pesquisas sobre socialização realizadas no Brasil estão sintonizadas com essa perspectiva: a socialização infantil é fundamental e deixa marcas indeléveis na personalidade política, mas acontecimentos cotidianos ou traumáticos afetam as atitudes ao longo da vida (BAQUERO E CUNHA, 2010). Nessa perspectiva, a socialização primária é a que ocorre na infância e na qual a família exerce uma grande influência, enquanto que a socialização secundária diz respeito ao processo subseqüente, que introduz o indivíduo em novos setores, em submundos institucionais (BERGER E LUCKMANN, 1985).

Em uma sociedade caracterizada pelas desigualdades social e política, como a brasileira, o processo de formação de atitudes políticas tende a se manifestar de forma incongruente, produzindo uma cultura política hibrida. Tanto no contexto familiar quanto na escola, a inconsistência entre o que se aprende sobre a democracia e as experiências que as pessoas têm no mundo real explicariam a assimetria entre a institucionalização de uma legitimidade jurídica e a ausência de confiança nas instituições políticas. Esse processo transbordaria para comportamentos político-eleitorais onde variáveis como o personalismo, o privatismo, o clientelismo e o patrimonialismo continuam a ter impacto significativo. O ambiente dentro do qual as normas e crenças são passadas de uma geração para outra, portanto, é de fundamental importância para avaliar o significado de pleitos eleitorais em sociedades que buscam solidificar o processo democrático.

Um aspecto que tem se institucionalizado como formador de atitudes e de comportamentos, ou seja, socialização política, é o que se refere aos meios de comunicação, particularmente a televisão que tende a homogeneizar as mentalidades, oferecendo a todos os indivíduos, de qualquer é idade, os mesmos conteúdos. Não por acaso, a mídia tem sido caracterizada como o quarto poder.

Os modelos construídos nos últimos anos têm-se debruçado maciçamente a explicar o poder persuasivo da mídia em pleitos eleitorais. O impacto dos meios de comunicação tem sido avaliado do ponto de vista de sua influência sobre a informação e o conhecimento dos indivíduos acerca do mundo político. Para alguns, a mídia tem um poder educativo significativo sendo responsável pelo aumento do nível de informação dos cidadãos acerca do mundo, bem como pelo do cinismo, apatia e desinteresse a respeito da política. Em outra perspectiva, o poder da mídia é reduzido, pois se argumenta que apesar da disponibilização dos meios de comunicação, o nível de conhecimento político de massa não melhorou nas últimas décadas. Teorias intermediárias constataram o "aprendizado de baixa saliência", no qual a mídia não é onipotente, mas exerce uma influência considerável (NEUMANN, 1986). 
Em tal cenário, o aprendizado político através da mídia é fragmentário e casual. À diferença dos cidadãos politicamente sofisticados, a pessoa comum não decodifica criticamente o conteúdo político. Constitui-se, dessa forma, uma premissa de que a informação estimula o interesse que, por sua vez, estimula o acúmulo de mais informação. Cabe destacar que as pesquisas sobre comportamento eleitoral têm recorrentemente mostrado que o cidadão bem informado é sempre minoritário. A maioria dos eleitores é desatenta e distante das informações sobre o mundo político, produzindo uma assimetria entre desenvolvimento institucional e uma cultura política atenta e participativa.

O resultado de um processo de socialização política incongruente produz situações políticas instáveis, onde, por exemplo, a identificação partidária é ambivalente e confusa. As pesquisas têm mostrado de forma consistente que na hora de votar, os eleitores consideram a pessoa do candidato mais importante do que o partido (BAQUERO, 2000), e esse processo de preferência eleitoral afeta fortemente outras atitudes políticas, servindo como ponto de referência para entender as predisposições de apoio ou rejeição a opções políticas.

Nesse sentido, não há um padrão universal de socialização política nem teoremas que se apliquem independente do tempo e do espaço. Na verdade são as circunstâncias históricas e sociais, que variam de país para país que se constituem em subsídios importantes explicativos do comportamento eleitoral.

Por isso, dado o contexto político brasileiro, as eleições presidenciais se caracterizariam em um momento importante do processo de socialização política, afetando toda a população adulta, pois durante o período de campanha eleitoral aumenta o nível de informação disponível, tornando-se a política uma pauta central nos meios de comunicação, tanto pela propaganda dos partidos como pela cobertura da mídia. A informação disponível e os debates públicos, portanto, seriam um fator de socialização, afetando os níveis cognitivos, afetivos e avaliativos dos cidadãos a respeito não apenas dos candidatos, mas também do sistema político e do regime.

A realização periódica e contínua de eleições deveria, assim, servir como fator de socialização para a consolidação de uma cultura política democrática e de participação. No entanto, o processo eleitoral não se dá no vazio, tendo como contraposto outros elementos de socialização, como as diversas outras instituições e organizações com que as pessoas têm contato cotidiano em sua vida, como a família, a igreja, as escolas e outros espaços de relação, que podem contribuir para a construção negativa do processo político, desfazendo o efeito positivo que poderia advir das eleições. 
A tradição psicossociológica, utilizada neste trabalho, examina a influência de contextos precedentes que mobilizam e motivam as pessoas a participar de atividades políticas, neste caso, as eleições presidenciais. São, esses contextos, que estão no âmago da abordagem referida e que possibilitam aplicar a teoria de socialização política. Uma das características das eleições presidenciais no Brasil, a partir de 1994, é a persistência de um padrão de blocos políticos homogêneos que se materializam de forma clara no segundo turno, caracterizando quase que uma disputa plebiscitária.

$\mathrm{Na}$ última década e meia, incluindo o período examinado neste trabalho (2002-2010) os resultados das eleições para presidente revelam um padrão relativamente estável do ponto de vista de preferências eleitorais, como pode ser visto no Gráfico 1.

\section{Gráfico 1}

\section{Resultados no primeiro e segundo turno das eleições presidenciais no Brasil 1994-2010 (\%)}

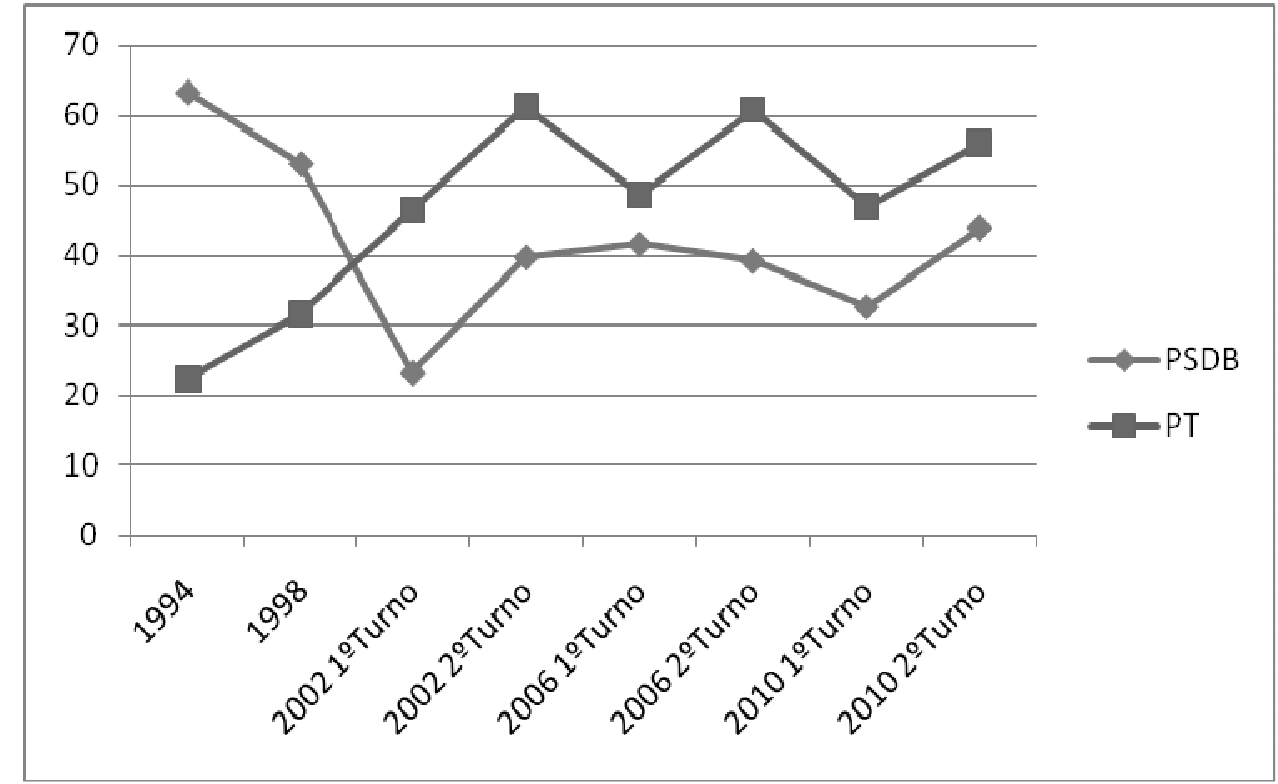

Fonte: TSE

A partir das eleições de 2002, constata-se o estabelecimento de um padrão "regular" de desempenho dos dois principais concorrentes nas eleições presidenciais, PSDB e PT. A única oscilação que chama a atenção é no primeiro turno de 2006, no qual o PSDB se aproximou do desempenho eleitoral do PT, 
BAQUERO, M.; GONZALEZ, R. S. Eleição, estabilidade democrática e socialização política...

provavelmente em virtude das denúncias de corrupção conhecidas como o processo do "mensalão", de 2005. No entanto, tal aproximação não se repetiu no segundo turno no qual o candidato à reeleição Luis Inácio da Silva praticamente repetiu a votação de 2002. Situação que se repetiu, em menor escala em 2010, com a eleição de Dilma Rouseff do PT. O que estes dados sugerem é que os eleitores, de maneira geral, não alteraram significativamente suas atitudes e comportamentos eleitorais no período examinado.

Poderia se afirmar que se institucionalizou uma postura de compreensão crítica, por parte dos eleitores, do que estava em jogo nessas eleições? As atitudes e comportamento eleitoral dos brasileiros mostram um amadurecimento político? Houve um processo de transmissão de valores de uma eleição para outra? Uma forma de começar a responder a essas indagações é examinando o padrão longitudinal de abstenção no período. Os dados estão no Gráfico 2.

\section{Gráfico 2}

\section{Índice de abstenção eleitoral no Brasil 2002-2010 (\%)}

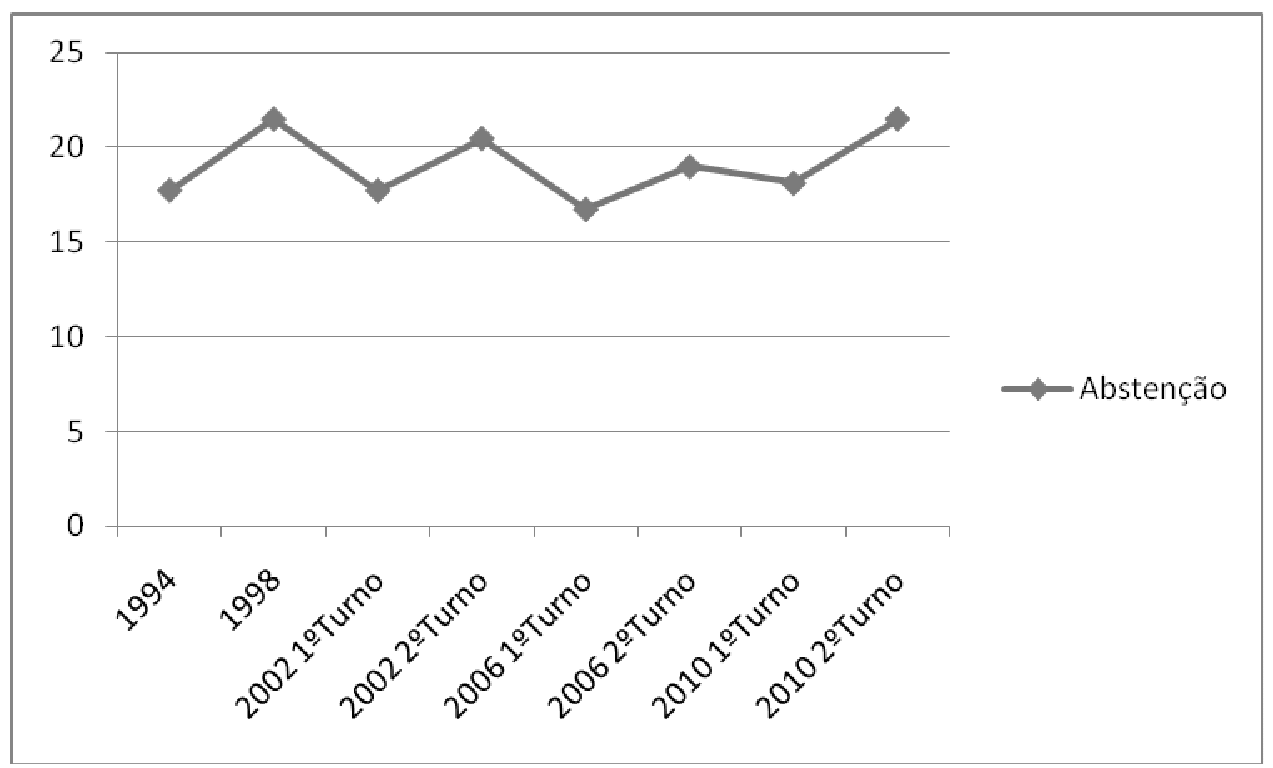

Fonte: TSE

À semelhança do voto, no padrão de abstenção eleitoral, também aparece uma regularidade longitudinal, sendo a média para os oito turnos de $19,1 \%$ sendo que o menor valor foi em 1994 com 17,7\%, e o maior em 1998 21,5\%. Além disso, ainda que o voto seja formalmente obrigatório, neste período não houve uma efetiva 
aplicação de punições pelo absenteísmo, mesmo entre os que não justificaram formalmente a ausência, com a aplicação periódica de anistia aos ausentes, o que poderia ter estimulado o aumento da abstenção (Tabela 1).

Tal "normalidade" seria indicativa de um processo em andamento de internalização de normas e valores democráticos capazes de fortalecer a democracia na sua dimensão mais substantiva? Tentaremos buscar resposta na análise dos dados.

\section{Tabela 1}

Votação nominal e abstenção nas eleições presidenciais - 1994-2010

\begin{tabular}{|l|l|l|}
\hline Ano & N Votação Nominal & N Abstenção \\
\hline 1994 & 51.462 .472 & 16.822 .410 \\
\hline 1998 & 67.722 .303 & 22.802 .823 \\
\hline $2002\left(1^{\circ}\right.$ Turno $)$ & 84.952 .512 & 20.448 .233 \\
\hline $2002\left(2^{\circ}\right.$ Turno $)$ & 86.164 .103 & 23.589 .188 \\
\hline $2006\left(1^{\circ}\right.$ Turno $)$ & 95.996 .733 & 21.092 .675 \\
\hline $2006\left(2^{\circ}\right.$ Turno $)$ & 95.838 .220 & 23.914 .714 \\
\hline $2010\left(1^{\circ}\right.$ Turno $)$ & 101.590 .153 & 24.610 .296 \\
\hline $2010\left(2^{\circ}\right.$ Turno $)$ & 99.453 .917 & 29.196 .864 \\
\hline
\end{tabular}

Fonte: TSE

\section{Metodologia}

Este trabalho utiliza como base de dados as pesquisas do Estudo Eleitoral Brasileiro (ESEB) de 2002. 2006 e 2010, e de forma complementar os dados da pesquisa do CEDEC de $1989^{2}$.

Os dados analisados a seguir buscam identificar se, passados tantos anos do início da redemocratização, os valores e atitudes políticos dos indivíduos têm se mantido estáveis, se sofrem mudanças contínuas ou conjunturais e se o

\footnotetext{
2 INTENÇÃO DE VOTO PARA PRESIDENTE VI-CEDEC I-1989- DAT/BR89.SET-00186. In: Banco de Dados do Centro de Estudos de Opinião Pública - CESOP.UNICAMP. Disponível em: $<$ http://www.cesop.unicamp.br/site/htm/busca/php>. Acessado em 07/07/2011.
} 
BAQUERO, M.; GONZALEZ, R. S. Eleição, estabilidade democrática e socialização política...

envelhecimento da população, com um tempo maior de experiência democrática, contribui na formação de uma cultura política congruente com a democracia. Um dos aspectos a ser analisado é se o fator idade gera diferenças em relação aos valores e atitudes manifestados pelos entrevistados. Conforme exposto anteriormente, há diferentes concepções sobre o processo de socialização e a influência (ou não) do envelhecimento na cultura política.

A proposição de Ortega e Gasset (1956) é de que as fases da vida humana podem ser divididas em cinco: a infância, a juventude, a etapa de inovação e polêmica, a etapa da maturidade e mando, e a velhice, separadas por períodos de cerca de 15 anos. Considerando que, desde a Constituição de 1988, a cada 16 anos, ingressa no processo político eleitoral um novo grupo de cidadãos e que as eleições presidenciais brasileiras ocorrem em intervalos pares, delimitando também a ocorrência dos levantamentos de dados como o ESEB, que ocorrem a cada 4 anos, este trabalho considerara um intervalo de 16 anos entre cada uma das coortes a serem comparadas.

Para verificar esses efeitos, a população foi dividida em três coortes, com interstício de 16 anos entre cada uma delas, baseando-se na teoria de Ortega y Gasset (1956). Tendo em vista que as amostras do ESEB são constituídas de eleitores, maiores de 16 anos, a primeira coorte é formada pelos jovens de 16 a 31 anos. A segunda, pela população adulta, de 32 a 47 anos. A terceira inclui a população maior de 48 anos. Em termos ideais seria possível propor uma quarta coorte, a acima dos 64 anos. Porém o tamanho das amostras tornaria muito pequeno o número de casos nesta faixa etária. Portanto, as populações acima de 48 anos são tratadas como constituída de adultos maduros.

Essas coortes foram cruzadas com diversas variáveis sobre o processo democrático e eleitoral. Busca-se identificar a existência de efeitos de geração ou de período. Os efeitos gerados pelas coortes podem ser de três tipos: (1) Efeito da geração ou da "coorte" se refere ao impacto que um evento tem nas atitudes e comportamentos dos indivíduos nele envolvidos; (2) Efeito do período aponta para eventos de grandes proporções políticas e/ou econômicas que impacta a população na sua totalidade, gerando mudanças estruturais nas atitudes e comportamentos da população afetada (as guerras, crises econômicas e escândalos políticos de grande magnitude); (3) Efeito idade (envelhecimento ou ciclo da vida) se direciona para a análise da influência da faixa de idade sobre as pessoas. Por exemplo, acredita-se que as pessoas mais velhas tendem a diminuir sua participação na arena política e os jovens a aumentá-la. Os jovens seriam mais orientados para se envolver em causas de transformação social e os idosos se tornariam mais passivos e conservadores (SCHMIDT, 2001). 
Com base nesses efeitos, podem ser identificados três momentos do processo socializador: (a) o da orientação para a comunidade (dos 5 aos 12 anos), (b) o da orientação para o regime (período da adolescência) e (c) o da atitude frente aos representantes políticos (final da adolescência e começo da vida adulta). O período de maior sensibilidade dos indivíduos quanto à formação de atitudes políticas seriam a adolescência e a juventude (NIEMI e HEPBURN, 1995).

Decorre desses momentos distintos da socialização política que as atitudes e comportamento político dos cidadãos de uma sociedade podem ser examinados dentro de uma retrospectiva histórica do cenário sob análise.

Metodologicamente, a forma para captar essas mudanças seria estudos do tipo painel ou longitudinais. Por meio desse tipo de estudos seria possível captar o efeito de um evento em $\mathrm{T}_{1}$ para $\mathrm{T}_{2}$ e, assim por diante. Um resultado importante desses estudos está na idéia de identificar o efeito de evento " $x$ " nos cidadãos por meio do processo de socialização política. Eleições, nesta perspectiva, seriam eventos significativos para analisar se atitudes e comportamentos políticos se modificam de um período a outro.

Contrapondo-se à análise longitudinal baseada em coorte, as mesmas dimensões serão analisadas tendo em vista a escolha eleitoral do entrevistado no segundo turno, tentando verificar se a dimensão da escolha política imediata é um fator que leva à mudança de atitudes de forma conjuntural. São analisadas três dimensões. Em primeiro lugar, uma dimensão de apoio difuso ao regime político, traduzida por questões sobre o apoio à democracia com duas formulações diferentes (Ver anexo, questões ESEB 23 e 51).

A segunda dimensão se refere à avaliação do processo político, envolvendo o apoio específico ao regime. São incluídas as variáveis: opinião se faz diferença quem governa o Brasil, sobre a influência do voto no que acontece no Brasil, satisfação com a democracia, se votaria caso o voto não fosse obrigatório e se as eleições presidenciais ajudam muito a melhorar a vida da população (Ver anexo, respectivamente questões ESEB 4, 5, 23, 53 e 55).

Por fim, a dimensão em relação ao processo político partidário, com a relação afetiva do eleitor em relação aos partidos e a importância dada ao vínculo do presidente com os partidos (Anexo, respectivamente questões ESEB 11, 12 e 54).

Estas variáveis foram cruzadas com a variável idade, escalonada em três coortes, conforme descrito acima e com a declaração de voto no segundo turno (Anexo questão ESEB 27). São analisadas freqüências relativas, obtidas por meio do processamento dos bancos de dados com o pacote estatístico SPSS. O resultado da análise dos dados é apresentado a seguir. 
BAQUERO, M.; GONZALEZ, R. S. Eleição, estabilidade democrática e socialização política...

\section{Dimensão de apoio difuso à democracia}

Verifica-se na análise da Tabela 2, no percentual de apoio difuso à democracia, medido pelas respostas "concorda muito" e "concorda um pouco", à afirmação de que a democracia tem alguns problemas, mas é melhor do que qualquer outra forma de governo, que os valores são assemelhados em relação às três coortes, se considerado o mesmo ano, mas sofrem uma queda nas três coortes no ano de 2006, voltando a subir a patamares ligeiramente mais altos aos de 2002 no ano de 2010. A variação é mais acentuada na resposta "concorda muito", do que na soma das respostas positivas, indicando uma diminuição da intensidade do apoio, sem, no entanto, uma transferência para o suporte ao regime contrário. Em todo o período o apoio foi superior a $75 \%$ em todos os anos e coortes.

Tabela 2

Opinião sobre se a democracia tem alguns problemas, mas é melhor do que qualquer outra forma de governo (Questão ESEB 22)

\begin{tabular}{|c|c|c|c|c|c|c|}
\hline \multirow{2}{*}{} & \multicolumn{3}{|c|}{ concorda muito } & \multicolumn{3}{c|}{$\begin{array}{c}\text { concorda muito e concorda } \\
\text { um pouco }\end{array}$} \\
\hline \multirow{2}{*}{ Coorte } & \multicolumn{3}{|c|}{ Ano } & \multicolumn{3}{c|}{ Ano } \\
\cline { 2 - 7 } & 2002 & 2006 & 2010 & 2002 & 2006 & 2010 \\
\hline $16-31$ & 55,6 & 43,8 & 60,2 & 86,2 & 78,9 & 87,1 \\
\hline $32-47$ & 55,8 & 43,6 & 60,7 & 84,0 & 80,5 & 86,8 \\
\hline $48+$ & 57,7 & 43,1 & 64,2 & 84,2 & 77,5 & 88,5 \\
\hline Total & 56,3 & 43,5 & 61,7 & 84,8 & 79,0 & 87,4 \\
\hline
\end{tabular}

n2002= 2513; n2006 = 1000; n2010 $=2000$

Fonte: ESEB 2002, 2006, 2010.

Esta variação concentrada na intensidade, mas não na opção pelo regime, pode ser constatada na comparação com a Tabela 3, em que a resposta é dada a uma questão de raciocínio binário, na qual o apoio à democracia é contraposto à aceitação de um regime autoritário. Neste caso, embora se verifique em 2006 uma pequena redução do apoio nas coortes adultas maiores de 32 anos, que resulta numa queda, se levada em conta a população total, em 2010 o apoio cresce em todas as coortes, aproximando-se dos patamares encontrados na Tabela 1 para o mesmo ano. 
Tabela 3

A democracia é sempre melhor que outra forma de governo (Questão ESEB 51)

\begin{tabular}{|c|c|c|c|}
\hline \multirow{2}{*}{ Coorte } & \multicolumn{3}{|c|}{ Ano } \\
\cline { 2 - 4 } & 2002 & 2006 & 2010 \\
\hline $16 \cdot 31$ & 72,0 & 72,4 & 84,7 \\
\hline $32 \cdot 47$ & 79,7 & 71,2 & 85,1 \\
\hline $48+$ & 77,8 & 69,5 & 86,3 \\
\hline Total & 76,5 & 71,2 & 85,4 \\
\hline
\end{tabular}

n2002 $=2513 ; \mathrm{n} 2006=1000 ; \mathrm{n} 2010=2000$

Fonte: ESEB 2002, 2006, 2010.

A variação encontrada entre as diferentes coortes é pequena e tende a se referir à queda encontrada no ano de 2006, o que pode indicar um impacto diferenciado dos eventos políticos do período (mensalão) no desencanto com o regime, de maneira conjuntural.

Tomadas de forma isolada, a análise destas variáveis indicaria uma socialização que incorpora valores democráticos em todas as faixas etárias, embora a percepção do regime seja igualmente afetada por fatores conjunturais. A seguir são apresentados os dados da dimensão de avaliação do processo político, verificando-se se são consistentes com esta proposição.

\section{Dimensão avaliação do processo político}

Um primeiro aspecto questionado foi a opinião sobre se faz diferença quem governa o Brasil. A resposta "faz uma grande diferença quem governa o Brasil" indica a percepção da importância do processo político na tomada de decisões. (Tabela 4). 
BAQUERO, M.; GONZALEZ, R. S. Eleição, estabilidade democrática e socialização política...

Tabela 4

Opinião sobre se faz diferença quem governa o Brasil Faz uma grande diferença quem governa o Brasil (Questão ESEB 4)

\begin{tabular}{|c|c|c|c|}
\hline \multirow{2}{*}{ Coorte } & \multicolumn{3}{|c|}{ Ano } \\
\cline { 2 - 4 } & 2002 & 2006 & 2010 \\
\hline $16 \cdot 31$ & 55,3 & 63,8 & 65,4 \\
\hline $32 \cdot 47$ & 60,1 & 63,4 & 69,8 \\
\hline $48+$ & 58,8 & 62,5 & 70,5 \\
\hline Total & 58,1 & 63,3 & 68,5 \\
\hline
\end{tabular}
n2002=2513; n2006=1000; $\mathrm{n} 2010=2000$
Fonte: ESEB 2002, 2006, 2010.

Neste caso há uma diferença constante entre a coorte jovem e as coortes de adultos mais velhos, embora no período tenha havido um crescimento constante de avaliação da importância nas três coortes, com um crescimento médio em torno de 20 pontos percentuais entre 2002 e 2010 nas três faixas, denotando uma percepção de valorização do processo de escolha dos governantes.

A Tabela 5 mostra a percepção sobre a influência do voto no que acontece no país, apresentando as respostas "o voto influência muito". Também neste caso há uma variação positiva entre 2002 e 2010, com uma estabilidade entre 2002 e 2006. Esta variação atinge principalmente os adultos maduros de mais de 48 anos. Os percentuais são semelhantes aos encontrados na Tabela 4.

\section{Tabela 5}

Opinião sobre a influência do voto no que acontece no Brasil Percentual Voto Influencia muito (Questão ESEB5)

\begin{tabular}{|c|c|c|c|}
\hline \multirow{2}{*}{ Coorte } & \multicolumn{3}{|c|}{ Ano } \\
\cline { 2 - 4 } & 2002 & 2006 & 2010 \\
\hline $16 \cdot 31$ & 65,4 & 67,1 & 68,8 \\
\hline $32 \cdot 47$ & 65,7 & 66,7 & 72,0 \\
\hline $48+$ & 59,6 & 59,1 & 73,1 \\
\hline Total & 63,8 & 64,7 & 71,3 \\
\hline
\end{tabular}

$\mathrm{n} 2002=2513 ; \mathrm{n} 2006=1000 ; \mathrm{n} 2010=2000$

Fonte: ESEB 2002, 2006, 2010.

Tratando da avaliação concreta do regime político, as respostas "muito satisfeito" e "satisfeito" à questão sobre o nível de satisfação com a democracia no 
Brasil têm percentuais muito abaixo das variáveis analisadas anteriormente, ainda que também um comportamento de crescimento positivo no período 2002-2010 em todas as coortes, ao ponto de passar de cerca de um terço para metade da população total satisfeita no período (Tabela 6).

\section{Tabela 6}

\section{Nível de satisfação com o funcionamento da democracia no Brasil Muito satisfeito e satisfeito (Questão ESEB23)}

\begin{tabular}{|c|c|c|c|}
\hline \multirow{2}{*}{ Coorte } & \multicolumn{3}{|c|}{ Ano } \\
\cline { 2 - 4 } & 2002 & 2006 & 2010 \\
\hline $16 \cdot 31$ & 27,6 & 40,4 & 44,2 \\
\hline $32 \cdot 47$ & 31,2 & 47,2 & 50,3 \\
\hline $48+$ & 40,4 & 48,3 & 56,5 \\
\hline Total & 32,5 & 44,7 & 50,2 \\
\hline
\end{tabular}

$\mathrm{n} 2002=2513 ; \mathrm{n} 2006=1000 ; \mathrm{n} 2010=2000$ Fonte: ESEB 2002, 2006, 2010.

A diferença existente entre os níveis de satisfação das diferentes coortes se mantém pouco alterada no período, mostrando um nível de satisfação maior entre os mais velhos em relação aos mais jovens.

Enquanto as variáveis anteriores examinavam posições avaliativas do regime como um todo, ao se passar para um contexto em que a situação pessoal tem peso na opinião, encontra-se uma diferença entre as faixas etárias, mostrando que as necessidades dos mais jovens têm sido menos atendidas pelas políticas governamentais. Se o apoio difuso dos jovens à democracia é tão consistente como os dos mais velhos, seu nível de satisfação com os resultados concretos, no entanto é menor.

No período 2002 a 2010 houve um crescimento do percentual de pessoas que considera que as eleições presidenciais ajudam muito a melhorar a vida da população, o que pode refletir o crescimento da popularidade do Presidente da República no período, embora com um nível inferior à satisfação com a democracia, indicando uma avaliação baseada em elementos pessoais e não nos institucionais. Há um crescimento contínuo desta opinião no período em todas as coortes, com um aumento pequeno entre 2002 e 2006, que, porém, é de cerca de 20 pontos percentuais entre 2002 e 2010, como visto na Tabela 7 
BAQUERO, M.; GONZALEZ, R. S. Eleição, estabilidade democrática e socialização política...

Tabela 7

Na sua opinião as eleições presidenciais Ajudam muito a melhorar a vida da população (Questão ESEB55)

\begin{tabular}{|c|c|c|c|}
\hline \multirow{2}{*}{ Coorte } & \multicolumn{3}{|c|}{ Ano } \\
\hline & 2002 & 2006 & 2010 \\
\hline $16 \cdot 31$ & 38,6 & 42,0 & 57,1 \\
\hline 32.47 & 42,0 & 48,7 & 60,7 \\
\hline $48+$ & 37,1 & 42,6 & 60,1 \\
\hline Total & 39,4 & 44,3 & 59,3 \\
\hline
\end{tabular}

Questionados sobre a disposição para a prática do principal ato relativo à democracia formal, a realização do voto nas eleições, foi constatada uma flutuação do percentual de respostas dos que afirmam que não votariam se o voto não fosse obrigatório, conforme pode ser visto na Tabela $8^{3}$.

Constata-se que entre 1989 e 2006 há um aumento constante em todas as coortes em relação aos eleitores que afirmam que não votariam se o voto fosse facultativo. Este percentual que é inferior a $40 \%$ em todas as coortes passa de $50 \%$ em todas elas em 2006, chegando próximo dos 60\% na faixa etária dos 32 aos 47 anos. Porém estes percentuais voltam aos valores aproximados de 2002, inclusive com uma queda mais acentuada na faixa etária acima dos 48 anos.

Aparentemente há um desencanto com os efeitos obtidos pelo voto, que é crescente da primeira eleição presidencial pós redemocratização em 1989 encontrando seu ápice em 2006, com uma recuperação parcial em 2010.

\footnotetext{
${ }^{3}$ Neste caso, além dos dados do período 2002 a 2010 foram utilizados na comparação os dados da pesquisa do CEDEC nas eleições presidenciais de 1989, disponibilizados pelo banco de dados do CESOP/Unicamp.
} 


\section{Tabela 8}

\section{Votaria caso o voto não fosse obrigatório? (Questão ESEB53)}

(Não votaria)

\begin{tabular}{|c|c|c|c|c|}
\hline \multirow{2}{*}{ Coorte } & \multicolumn{4}{|c|}{ Ano } \\
\cline { 2 - 5 } & 1989 & 2002 & 2006 & 2010 \\
\hline $16 \cdot 31$ & 39,3 & 41,3 & 52,2 & 43,9 \\
\hline $32 \cdot 47$ & 37,2 & 48,3 & 58,1 & 49,2 \\
\hline $48+$ & 36,5 & 46,8 & 54,0 & 40,8 \\
\hline Total & 37,9 & 45,5 & 54,6 & 44,6 \\
\hline
\end{tabular}

n2002 = 2513; n2006 = 1000; n2010 $=2000$

Fonte: CEDEC,1989 ESEB 2002, 2006, 2010.

Esta posição é contraditória em relação ao reconhecimento da importância do voto e de quem governa para o país. Ao cruzar a variável referente ao voto obrigatório com as anteriores, se, por óbvio, aqueles que consideram que não faz diferença quem governa, que o voto não influencia o que acontece no país, não vêem benefícios para a população nas eleições presidenciais ou que estão muito insatisfeitos com a democracia, também majoritariamente não votariam se o voto fosse facultativo, percentuais em torno de $40 \%$ daqueles com a posição oposta também não se disporiam a votar se não fossem obrigados, indicando a presença de uma cultura política sujeita (ALMOND E VERBA, 1965), com pessoas que reconhecem a importância das instituições democráticas, mas não estão dispostos a participar.

Em relação a esta dimensão, embora algumas variáveis apresentem variação contínua em um sentido positivo (Tabelas 4, 5, 6 e 7), indicando o reconhecimento da importância do processo político, com impacto em todas as idades, o que caracterizaria um processo de socialização que atinge as faixas adultas, por outro lado a posição sobre a obrigatoriedade do voto contrasta, mostrando um impacto conjuntural negativo. Porém, observa-se pelo Gráfico 2 que esta posição não teve impacto significativo no comportamento efetivo dos eleitores em relação à abstenção eleitoral. As variações também são constatadas entre as coortes, demonstrando que o elemento etário pode influir na percepção da realidade e na modificação das atitudes.

Verifica-se em seguida se este comportamento das variáveis também ocorre em relação à dimensão político partidária, que envolve elementos formais do processo político. 
BAQUERO, M.; GONZALEZ, R. S. Eleição, estabilidade democrática e socialização política...

\section{Dimensão político partidária}

Para a questão se havia algum partido político do qual gostasse, encontramos um percentual muito semelhante nos anos de 2002 e 2010, em todas as coortes, em torno de $48 \%$. Este percentual cai para em torno de $33 \%$ no ano de 2006, como pode ser visto na Tabela 9.

Tabela 9

De um modo geral, existe algum partido político que o(a) Sr(a) goste? (Questão ESEB11) (Resposta sim)

\begin{tabular}{|c|c|c|c|}
\hline \multirow{2}{*}{ Coorte } & \multicolumn{3}{|c|}{ Ano } \\
\cline { 2 - 4 } & 2002 & 2006 & 2010 \\
\hline $16 \cdot 31$ & 48,3 & 31,3 & 48,4 \\
\hline $32-47$ & 49,0 & 34,0 & 48,8 \\
\hline $48+$ & 46,1 & 35,1 & 45,8 \\
\hline Total & 47,9 & 33,2 & 47,7 \\
\hline
\end{tabular} n2002= 2513; n2006= 1000; n2010= 2000
Fonte: ESEB 2002, 2006, 2010.

Esta mudança indicaria um aumento da descrença nos partidos, no contexto da crise política de 2005-2006. Cabe então verificar as mudanças em relação ao percentual do partido apontado como preferido por aqueles que responderam positivamente à questão anterior. Há três partidos cujos percentuais se destacam na resposta do qual partido gosta: PT, PSDB e PMDB. Os dois primeiros responsáveis pelo principal enfrentamento nas eleições presidenciais. O terceiro ainda aparecendo como maior partido do país, embora sem o mesmo prestígio na apresentação de candidaturas à presidência. No entanto os dados contradizem a expectativa de perda de suporte dos partidos de situação envolvidos nos escândalos políticos do final do primeiro mandato do Presidente Lula. 
Tabela 10

Partido que gosta (Questão ESEB12)

\begin{tabular}{|c|c|c|c|c|c|c|c|c|c|}
\hline \multirow{3}{*}{ Coorte } & \multicolumn{9}{|c|}{ Partido } \\
\hline & \multicolumn{3}{|c|}{ PT } & \multicolumn{3}{|c|}{ PMDB } & \multicolumn{3}{|c|}{ PSDB } \\
\hline & 2002 & 2006 & 2010 & 2002 & 2006 & 2010 & 2002 & 2006 & 2010 \\
\hline $16 \cdot 31$ & 61,8 & 61,4 & 57,7 & 10,2 & 7,1 & 8,0 & 11,4 & 19,7 & 15,6 \\
\hline 32.47 & 54,8 & 69,5 & 59,2 & 16,6 & 12,4 & 11,0 & 8,9 & 10,5 & 17,9 \\
\hline $48+$ & 42,0 & 65,7 & 57,1 & 18,6 & 13,1 & 14,0 & 7,7 & 9,1 & 15,3 \\
\hline Total & 53,6 & 65,3 & 58,0 & 15,0 & 10,6 & 10,9 & 9,4 & 13,6 & 16,3 \\
\hline
\end{tabular}

O percentual de entrevistados que diz gostar do PT ampliou-se entre 2002 e 2006, em especial nas faixas etárias de maior idade. Estes percentuais caíram parcialmente em 2010. Há indícios de envelhecimento dos apoiadores do partido, uma vez que a única coorte na qual se constata queda para patamares inferiores a 2002 é a dos mais jovens. No mesmo período, o PMDB teve um decréscimo de simpatizantes em todas as coortes. Já o PSDB cresceu em apoio entre 2002 e 2010 em todas as coortes, dobrando os percentuais nas coortes mais velhas, mas crescendo, ainda que menos, entre os mais jovens, enquanto os dois outros partidos tiveram decréscimo nesta faixa etária (Tabela 10).

Assim, a queda do número de simpatizantes que se identifica com um partido no ano de 2006 não afetou particularmente o PT com uma migração para partidos de posição, salvo entre os mais jovens. O crescimento conjuntural em 2006 do PSDB nesta faixa, porém, não foi capaz de erodir de forma profunda as bases do partido governista. Embora aquele tenha aumentado o número de simpatizantes no período, tanto em números relativos como absolutos, continua com um percentual quatro vezes menor do que o PT.

Falando sobre os efeitos de contexto, identifica-se uma mudança, no ano de 2006, sobre a desejabilidade do Presidente da República estar identificado com um partido. Esta posição é majoritária em todas as coortes em 2002 e 2010, beirando os $60 \%$, mas cai para abaixo de $50 \%$ em 2006, salvo na coorte intermediária. A queda desta avaliação, no entanto, é menor do que a verificada na Tabela 9 sobre a simpatia pelos partidos. Assim, mesmo aqueles que não gostam de um partido específico, em alguns casos reconhecem que é melhor que o Presidente se identifique com um. Estes percentuais indicam um reconhecimento positivo da 
BAQUERO, M.; GONZALEZ, R. S. Eleição, estabilidade democrática e socialização política...

maioria dos partidos como um mecanismo desejável à governabilidade democrática, (Tabela 11).

Tabela 11

0 que é melhor, um presidente da república que seja identificado com um partido (Questão ESEB54)

\begin{tabular}{|c|c|c|c|}
\hline \multirow{2}{*}{ Coorte } & \multicolumn{3}{|c|}{ Ano } \\
\hline & 2002 & 2006 & 2010 \\
\hline $16-31$ & 62,4 & 46,7 & 59,6 \\
\hline 32.47 & 61,0 & 50,6 & 58,1 \\
\hline $48+$ & 51,6 & 47,5 & 60,7 \\
\hline Total & 58,7 & 48,2 & 59,5 \\
\hline
\end{tabular}

Os dados indicam que a dimensão da vida partidária é a mais sensível às influências conjunturais, com um comportamento das variáveis semelhante à posição sobre o exercício do voto. Porém, os dados indicam que esta conjuntura afeta de maneira diferente os sujeitos que têm identificação partidária, podendo ser interpretado que esta identidade depende menos dos processos de socialização.

Tentando identificar a influência do contexto eleitoral, verifica-se em seguida se a escolha eleitoral teria uma maior capacidade explicativa das atitudes que a idade dos sujeitos.

\section{Dimensões atitudinais e escolha eleitoral}

Um dos aspectos a ser analisado para podermos robustecer as conclusões dos dados apresentados é o grau de influência da posição do eleitor no contexto eleitoral em relação a suas respostas.

Como o ESEB é um estudo pós-eleitoral, poderia haver uma influência do resultado eleitoral na opinião do eleitor, reforçando um sentimento de satisfação daqueles que apoiaram o candidato vencedor ou de desencanto ou senso crítico por parte dos que viram o seu candidato ser derrotado. Assim, algumas das mesmas variáveis apresentadas anteriormente foram cruzadas com a opção de voto no segundo turno informada pelo eleitor na pesquisa. Neste caso são comparados os percentuais totais da população, desconsiderada a divisão por faixa etária. Os resultados estão na Tabela 12 . 
Nota-se um impacto maior com a variável referente ao grau de satisfação com a democracia. Em 2002, em um contexto anterior à posse do Presidente Lula, o percentual de eleitores de Serra demonstrava estar ligeiramente mais satisfeito com a democracia do que os de Lula. Nos anos de 2006 e 2010 os eleitores de Lula e Dilma estão quase 30 pontos percentuais mais satisfeitos do que os de Alckmin e Serra. Na comparação entre os anos de 2002, 2006 e 2010 este comportamento se reproduz na maioria das demais variáveis.

Contudo, a posição sobre a não participação, no caso de voto facultativo, tem pequenas diferenças entre os eleitores de cada um dos partidos. Em relação à influência do voto e se as eleições ajudam muito a melhorar o país, os percentuais dos eleitores do PT são relativamente maiores dos que os do PSDB.

Em relação a se faz diferença quem governa o país, ainda que mantendo as diferenças, os percentuais crescem em ambos os grupos chegando em 2010 a serem maiores entre os eleitores de Serra do que de Dilma, o que indica que reconhecer a importância de quem governa não significa estar ao seu lado. 
BAQUERO, M.; GONZALEZ, R. S. Eleição, estabilidade democrática e socialização política...

Tabela 12

Dimensões culturais de avaliação e suporte da democracia $X$ voto para presidente no segundo turno das eleições

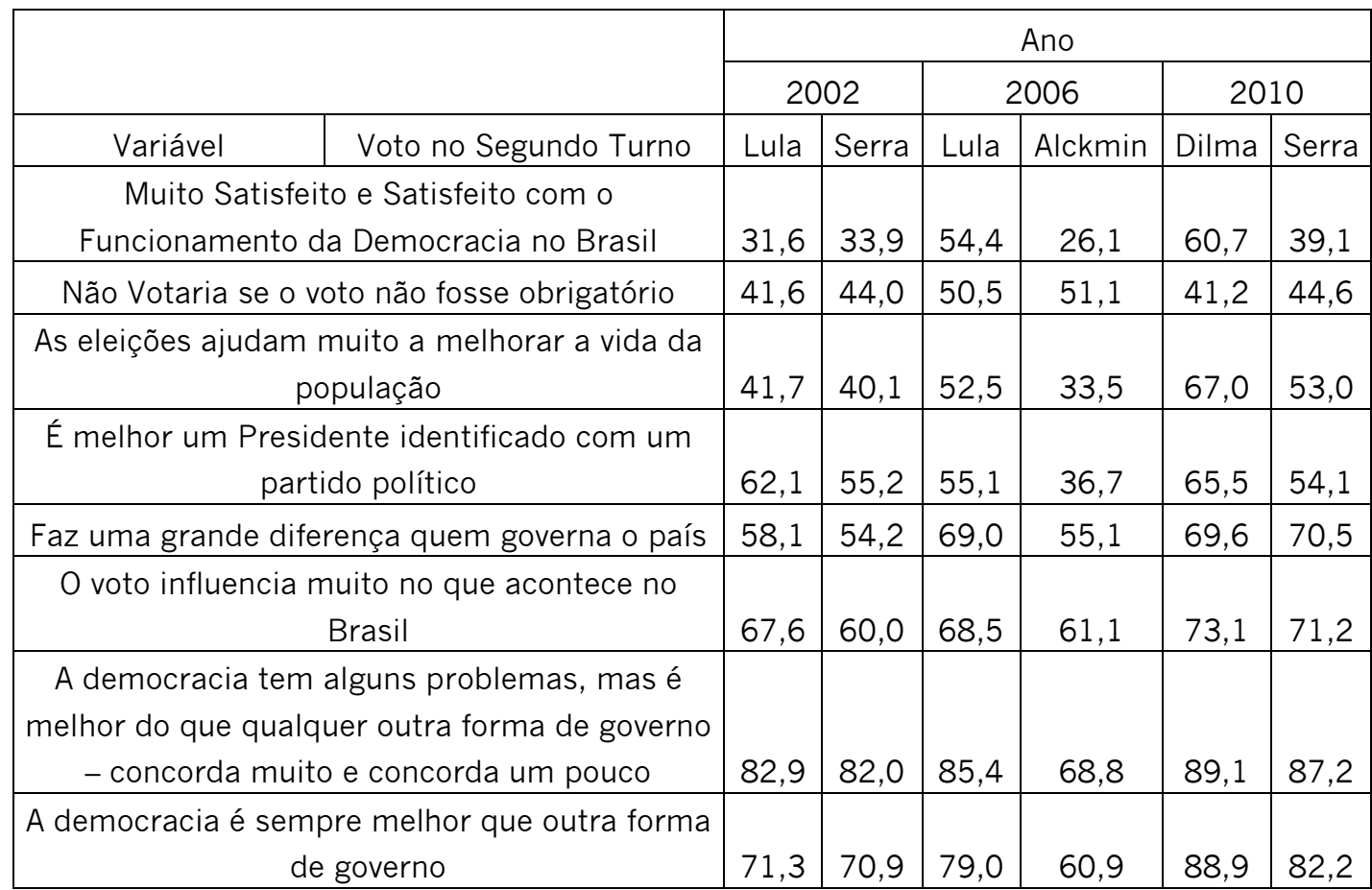

$\mathrm{n} 2002=2513 ; \mathrm{n} 2006=1000 ; \mathrm{n} 2010=2000$

Fonte: ESEB 2002, 2006, 2010.

O percentual dos que consideram que o presidente deve ser identificado com um partido cai em 2006, mas muito mais entre os eleitores de Alckmin, indicando que a crítica ao eventual envolvimento do partido do Presidente com escândalos afeta mais os oposicionistas.

Quanto ao apoio difuso à democracia, embora este seja maior entre os apoiadores do candidato vencedor, em especial em 2006, ele se mantém alto entre os eleitores de ambos os candidatos, não apresentando a ruptura institucional como uma saída aceitável para a derrota eleitoral. Para ambas as questões há um suporte crescente dos eleitores dos vencedores. Entre os derrotados, o ano de 2006 mostra uma distância maior em relação aos percentuais de ambos os candidatos, que são muito semelhantes nos outros anos. 


\section{À guisa de conclusão}

A pequena diferença entre as coortes etárias indica a existência de um conjunto de valores que tem sido incorporado pelos que ingressam no processo político, não havendo grandes distinções atitudinais entre as gerações. Os eventos conjunturais afetam igualmente todas as gerações.

O aumento dos percentuais de adesão a valores que são identificados com a estabilidade democrática não pode ser atribuído exclusivamente ao sucesso eleitoral e à satisfação dos eleitores cujo candidato obteve sucesso, uma vez que ocorre, mesmo que em menor medida, entre os apoiadores do candidato derrotado.

Por outro lado, a mudança de atitudes não é explicada pela mera mudança geracional, contrapondo a perspectiva defendida por Ronald Inglehart (INGLEHART, 1990, INGLEHART E WELZEL, 2009), de que a mudança ocorre pela substituição de gerações. As mudanças são observadas em todas as coortes e, em alguns casos afetam mais fortemente os grupos etários de mais idade.

A avaliação sobre a influência do voto e de quem governa foi crescente. A confiança nos partidos e na desejabilidade do vínculo do presidente foi abalada. Reflete-se na avaliação da democracia e do voto obrigatório. Porém o percentual de abstenção tem se mantido relativamente constante, mesmo nos períodos em que há menor adesão à responsabilidade pelo voto, indicando que a regra de obrigatoriedade ainda surte algum efeito, mesmo que de forma simbólica.

As coortes por idade não parecem explicar as diferenças na população. Os percentuais são semelhantes e as variações dentro do período, quando ocorrem, afetam todas as coortes na mesma direção.

Há dois tipos de movimentos no período. Um, relativo às variáveis em que há um crescimento contínuo no período, como a opinião sobre a importância do voto e se faz diferença quem governa o país, e se as eleições presidenciais ajudam a melhorar a vida da população. Nesses casos há indicação de que há uma mudança de atitude relativamente estável, na direção de conviç̧ões que são favoráveis à estabilidade democracia e que afetam todas as faixas etárias. Aqui a manutenção de processos eleitorais contínuos poderia ser considerada um fator positivo para uma socialização democrática. Porém há variáveis que têm uma queda dos percentuais em 2006 com a retomada dos valores de 2002 em 2010, comportando. se como uma curva em forma de U. É o caso das medidas de apoio difuso à democracia, desejabilidade de identificação partidária do presidente e simpatia pelos partidos políticos e disposição de votar no caso de voto facultativo.

Assim, embora se observe uma atitude positiva perante o processo democrático, permanece uma desconfiança em relação a dois elementos do modelo de democracia representativa: os partidos e o exercício do voto, cuja valoração é 
BAQUERO, M.; GONZALEZ, R. S. Eleição, estabilidade democrática e socialização política...

afetada pelos elementos conjunturais como os escândalos políticos que se repetem periodicamente.

O conjunto dos dados indica que embora a preferência eleitoral do cidadão afete a sua posição a respeito das diversas questões, a diferença entre os que apoiaram vencedores e vencidos não é suficiente para explicar a variação das diversas dimensões no período 2002-2010.

Variáveis que dependem de satisfação pessoal, como a satisfação com a democracia, parecem ser mais afetadas do que as que envolvem avaliação das instituições, demonstrando a consolidação de valores em relação ao processo democrático que são afetados por eventos políticos de impacto, como a crise política de 2005-2006, mas não pelo jogo político eleitoral. Embora o momento presente indique uma mudança positiva no período recente, o fato de que a adesão a valores fundamentais para o funcionamento do regime, como o funcionamento do sistema partidário, a participação pelo voto e mesmo o apoio abstrato à democracia são afetados por fatores conjunturais, mostra uma incongruência com as atitudes expostas anteriormente, uma vez que afetam as percepções de forma sistêmica e não apenas em relação ao grupo ou partido político diretamente envolvido.

A valorização da democracia, a percepção positiva da importância da escolha dos governantes e das eleições na vida das pessoas, ao mesmo tempo em que flutua o valor dado aos partidos e seu vínculo com os governantes, aponta para uma socialização que é mais congruente com um modelo de democracia plebiscitária ou delegativa, do que com a representação de caráter poliárquico.

Neste sentido, costata-se a existência de uma cultura política híbrida, que evoluiu em relação ao passado, mas que mostra contradições presentes em todas as gerações, não sendo previsível que seja um problema a ser resolvido pela mera recomposição da população, com o ingresso de novos cidadãos na vida política. Isto ocorre na medida em que o comportamento dos mais jovens reproduz os mesmos aspectos de desconfiança sobre a política dos mais velhos, que de alguma forma impedem que as instituições democráticas formais funcionem corretamente, garantindo uma democracia realmente existente de igual qualidade daquela que é projetada na expectativa teórica dos analistas institucionais.

O período compreendido pelos dados ainda é pequeno para conclusões mais definitivas, os oito anos analisados não permitem a comparação pelo ingresso de uma geração inteiramente nova, dos que nasceram no mesmo momento em que o grupo etário anterior ingressava na vida política eleitoral. Porém, as análises realizadas nos dão pistas de caminhos a seguir em novas investigações, verificando se as tendências encontradas têm seguimento ou se alteram, bem como a busca de identificação de novos fatores de socialização em um mundo em constante 
transformação dos meios de acesso à informação e de interação entre os indivíduos, em especial pelas novas tecnologias surgidas ou popularizadas na última década.

\section{Referências Bibliográficas}

ALBUQUERQUE, J. A. G. "Identidade, oposição e pragmatismo: uma teoria política do voto". Lua Nova, São Paulo, n²6, 1992.

ALMOND, G.; VERBA, S. The civic culture: political attitudes and democracy in five nations. Boston: Little, Brown \& Co, 1965.

ANTUNES, J. R. S. "Identificação partidária e comportamento eleitoral: fatores estruturais, atitudes e mudança no sentido do voto". 2008. 508 f. Tese (Doutorado em Psicologia Social). Faculdade de Psicologia e de Ciências da Educação, Universidade de Coimbra, Coimbra, 2008.

BALBACHEVSKY, E.; HOLZHACKER, D. O. "Identidade, oposição e pragmatismo: O conteúdo estratégico da decisão eleitoral em 13 anos de eleições". Opinião Pública, Campinas, vol. 10, $n^{\circ} 2$, p. 242-253, out., 2004.

BAQUERO, M. A vulnerabilidade dos partidos políticos e a crise da Democracia na América Latina. Porto Alegre: Editora da UFRGS, 2000.

"Eleições e capital social: uma análise das eleições presidenciais no Brasil (2002. 2006)". Opinião Pública, Campinas, vol. 13, n² 2, p.231-259, nov., 2007.

BAQUERO, M.; CUNHA, P. A corrupção como limite à participação política juvenil: um estudo em democracias sul-americanas. In: BAQUERO, R.; NAZZARI, R. K. (orgs.). Formas de (ex) pressão juvenil e (in)visibilidade social. Cascavel: Coluna do Saber, 2010, v, p. 55-78.

BERGER, P.; LUCKMANN, T. A construção social da realidade. Petrópolis: Vozes, 1985.

CAMPBELL, A., CONVERSE, P.E., MILLER, W.E. STOKES, D.E. The American voter. New York: Wiley, 1960.

CASTRO, M. M. M. "Sujeito e estrutura no comportamento eleitoral". Revista Brasileira de Ciências Sociais: ANPOCS, São Paulo, nº. 20, 1992.

"Determinantes do comportamento eleitoral: a centralidade da sofisticação política". 1994. 239f. Tese (Doutorado em Ciência Política), IUPERJ, Rio de Janeiro.

DOWNS, A. Uma teoria econômica da democracia. São Paulo: EDUSP, 1999.

EASTON, D. A Framework for Political Analysis. Englewood Cliffs, NJ: Prentice-Hall, 1965. 
BAQUERO, M.; GONZALEZ, R. S. Eleição, estabilidade democrática e socialização política...

EASTON, D.; DENNIS, J. Children in political system: origins of political legitimacy. New York: McGraw.Hill, 1969.

FIGUEIREDO, M. A decisão de voto. São Paulo: IDESP/Sumaré, 1991.

HYMAN, H. Political socialization: a study in the psychology of political behavior. Glencoe: The Free Press, 1959.

INGLEHART, R. Culture shift in advanced industrial society. New Jersey: Princeton University Press, 1990.

INGLEHART, R.; WELZEL, C. Modernização, mudança cultural e democracia. São Paulo: Ed. Verbena, 2009.

JENNINGS, M. K.; NIEMI, R. G. The political character of adolescence: the influence of families and schools. Princeton: Princeton University Press, 1974.

LAZARSFELD, P., BERELSON, B.; GAUDET, H. The People's choice. New York: Columbia University Press, 1968.

NEUMANN, W. R. The paradox of mass politics: knowledge and opinion in the American electorate. Cambridge e London: Harvard University Press, 1986.

NIEMI, R.; HEPBURN, M. "The rebirth of political socialization". Perspectives on Political Science, vol.24, $\mathrm{n}^{\circ}$ 1, p. 7-16, 1995.

ORTEGA y GASSET, J. En torno a Galileo: esquema de las crisis. Madri: Revista del Ocidente, 1956.

PERCHERON, A. La formation politique de l'individu. In: PARODI, J. L. La Politique. Paris: Hachette, p. 142-168, 1971.

REIS, F. W. "Identidade, política e a teoria da escolha racional". Revista Brasileira de Ciências Sociais, p. 26-38, 1988.

SCHMIDT, J. P. Juventude e Política no Brasil - a socialização dos jovens na virada do milênio. Santa Cruz do Sul: EDUNISC, 2001.

SIGEL, R. S. (ed.). Political Learning in adulthood: a sourcebook of theory and research. Chicago/Londres: The University of Chicago Press, 1989. 
SILVEIRA, F. "Escolha intuitiva: nova modalidade de decisão do voto". Opinião Pública: Campinas, vol.2, n² 2, p. 61-72, dez., 1994.

\section{ANEXO 1 - Questões originais}

Abaixo são reproduzidas as questões conforme a formulação. Os números se referem aos questionários e bancos de dados do ESEB de 2006 e 2010.

ESEB4) (MOSTRAR CARTÃO ESEB4) Algumas pessoas dizem que faz uma grande diferença quem governa o Brasil. Outras pessoas dizem que não faz diferença quem governa o Brasil. Gostaria que o(a) Sr(a) desse uma nota de 1 a 5. O 1 significa que faz uma grande diferença quem governa, e o 5 que NÃO faz nenhuma diferença quem governa o Brasil. O que o(a) $\operatorname{Sr}(a)$ acha? (ESTIMULADA E ÚNICA)

ESEB5) (MOSTRAR CARTÃO ESEB5) Algumas pessoas dizem que o nosso voto influencia muito no que acontece no Brasil, outras dizem que o nosso voto NÃO influencia nada no que acontece no Brasil. Gostaria que o(a) Sr(a) desse uma nota de 1 a 5 . O 1significa que o nosso voto influencia muito, e 5 significa que o nosso voto NÃO influencia nada no que acontece no Brasil. O que o(a) $\operatorname{Sr}(a)$ acha?

ESEB11) De um modo geral, existe algum partido político que o(a) Sr(a) goste? (ESPONTÂNEA E ÚNICA) 1 - SIM 0 - NÃO (PULE P/ ESEB14) 77 - NS (PULE P/ ESEB14) 99 - NR (PULE P/ ESEB14)

ESEB12) Qual partido o(a) Sr(a) gosta? (ESPONTÂNEA E MÚLTIPLA)

ESEB22) De uma maneira geral, o(a) Sr(a) está muito satisfeito(a), satisfeito(a), pouco satisfeito(a) ou não está satisfeito(a) com o funcionamento da democracia no Brasil? (ESTIMULADA E ÚNICA) (ENTREVISTADOR: ACEITAR A OPÇÃO 'NEM SATISFEITO NEM INSATISFEITO COMO ESPONTÂNEA.

ESEB23) Na sua opinião.. (LER OPÇÕES) (ESTIMULADA E ÚNICA) (ENTREVISTADOR: ACEITAR A OPÇÃO TANTO FAZ COMO ESPONTÂNEA) 1 A democracia é sempre melhor que qualquer outra forma e governo OU 2 Em algumas situações é melhor uma ditadura do que uma democracia 3 Tanto faz / nenhuma das duas é melhor. 77 NS 99 NR 
BAQUERO, M.; GONZALEZ, R. S. Eleição, estabilidade democrática e socialização política...

ESEB27) E no segundo turno, o(a) sr(a) votou em Lula ou Alckmin? (Lula ou Serra, 2002; Dilma ou Serra, 2010).

ESEB51) Agora, mudando de assunto: A democracia tem alguns problemas, mas é melhor do que qualquer outra forma de governo. O(a) $\operatorname{Sr}(a)$ concorda ou discorda dessa afirmação? Muito ou pouco? (ESTIMULADA E ÚNICA) (INSTRUÇÕES: pergunta em duas etapas. Aceitar a resposta "nem concorda nem discorda" como resposta espontânea.

ESEB53) Se o voto não fosse obrigatório o(a) Sr(a) votaria? (ESPONTÂNEA E ÚNICA). 1 - SIM 0 - NÃO 55 - TALVEZ/DEPENDE 77 - NS 99 - NR

ESEB54) O que é melhor, um presidente da república que ..... (ESTIMULADA E ÚNICA) 1 Seja identificado com um partido político OU 2 Um presidente que não dê importância para os partidos? 77 NS 99 NR

ESEB55) Na sua opinião as eleições presidenciais ..... (ESTIMULADA E ÚNICA) 1 Ajudam muito 2 Ajudam um pouco 3 Não ajudam a melhorar a vida da população. 77 NS 99 NR

Marcello Baquero - nupesal@yahoo.com.br

Rodrigo Stumpf - rodrigo.stumpf@terra.com.br

Recebido para publicação em setembro de 2011. Aprovado para publicação em outubro de 2011 